
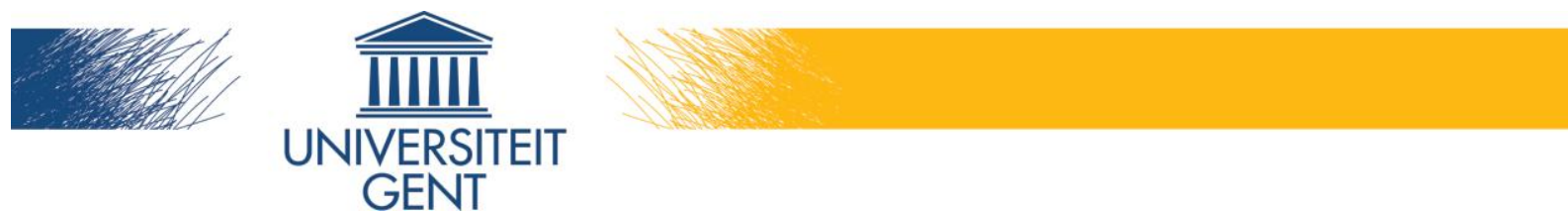

biblio.ugent.be

The UGent Institutional Repository is the electronic archiving and dissemination platform for all UGent research publications. Ghent University has implemented a mandate stipulating that all academic publications of UGent researchers should be deposited and archived in this repository. Except for items where current copyright restrictions apply, these papers are available in Open Access.

This item is the archived peer-reviewed author-version of:

Title: Dried Blood Spots in Toxicology: from the Cradle to the Grave?

Authors: Christophe P. Stove, Ann-Sofie M.E. Ingels, Pieter M.M. De Kesel and Willy E. Lambert In: Critical Reviews in Toxicology, 42(3), 230-243, 2012

To refer to or to cite this work, please use the citation to the published version:

Christophe P. Stove, Ann-Sofie M.E. Ingels, Pieter M.M. De Kesel and Willy E. Lambert (2012). Dried Blood Spots in Toxicology: from the Cradle to the Grave? Critical Reviews in Toxicology, 42(3), 230243. doi:10.3109/10408444.2011.650790 


\section{Dried Blood Spots in Toxicology: from the Cradle to the Grave?}

Christophe P. Stove*, Ann-Sofie M.E. Ingels, Pieter M.M. De Kesel and Willy E. Lambert Laboratory of Toxicology, Faculty of Pharmaceutical Sciences

Ghent University

Harelbekestraat 72

9000 Ghent, Belgium

*: Corresponding Author

Tel.: 003292648136

Fax: 003292648183

christophe.stove@ugent.be

OUTLINE

Introduction

Dried Blood Spots - Sources

Analysis of Therapeutic Drugs -Toxicokinetics

Analysis of Drugs of Abuse

Forensic Toxicology

Ease of sampling

Stabilizing effect

Newborn Screening

Analysis of Environmental Contaminants

Newborn Screening

Biomonitoring of Animals

Elemental Analysis

Conclusion and Future Perspectives

2 


\begin{abstract}
About a century after its first described application by Ivar Bang, the potential of sampling via dried blood spots (DBS) as an alternative for classical venous blood sampling is increasingly recognized. Perhaps best known is the use of DBS in newborn screening programs, ignited by the hallmark paper by Guthrie and Susi half a century ago. However, it is only recently that both academia and industry have recognized the many advantages that DBS sampling may offer for bioanalytical purposes, as reflected by the strong increase in published reports during the last few years. Currently, major DBS applications include newborn screening for metabolic disorders, epidemiological surveys (e.g. HIV monitoring), therapeutic drug monitoring (TDM), as well as toxicology. In this review, we provide a comprehensive overview of the distinct subdisciplines of toxicology for which DBS sampling has been applied. DBS sampling for toxicological evaluation has been performed from birth until autopsy, aiming at the assessment of therapeutic drugs, drugs of abuse, environmental contaminants, toxins, as well as (trace) elements, with applications situated in fields as toxicokinetics, epidemiology and environmental and forensic toxicology. We discuss the strengths and limitations of DBS in the different subdisciplines and provide future prospects for the use of this promising sampling technique in toxicology.

3
\end{abstract}




\section{Introduction}

Already about a century ago, the potential of using dried blood spots (DBS) for biomonitoring was recognized by Ivar Bang, who demonstrated its usefulness for glucose monitoring (Bang, 1913). However, it took another 50 years before the use of DBS became more widespread, ignited by the seminal paper by Guthrie and Susi, who demonstrated the applicability of screening newborn DBS for phenylketonuria (Guthrie and Susi, 1963). Since then, an ever increasing amount of biomarkers has been included in DBS newborn screening programs worldwide (Seashore and Seashore, 2005, Watson et al., 2006, Garg and Dasouki, 2006, Bodamer et al., 2007, Chace, 2009). Apart from its use for newborn screening, DBS sampling has also been applied in animals, children, adults and even post mortem, its applications rising rapidly the last few years, covering the analysis of DNA (e.g. HIV, serotyping of bacteria, genotyping), proteins (e.g. enzyme activity or antibody-based analysis), small molecules (endogenous or exogenous, e.g. amino acids or therapeutic drugs), as well as trace elements (e.g. lead).

This review aims at covering the different subdisciplines of toxicology for which DBS sampling has been reported. More specifically, we will discuss the application of DBS for the analysis of therapeutic drugs (toxicokinetics), drugs of abuse, environmental contaminants, toxins and (trace) elements. Topics not covered by this review are the use of DBS for therapeutic drug monitoring (TDM) and for metabolic screening, two fields which, although having some overlap with toxicology because toxic effects may be encountered, are considered as distinct disciplines. The interest in using DBS for the purpose of TDM (including clinical toxicology), with sampling either in the clinic or at the patient's home, has recently shown a strong increase. Also here, apart from follow-up and reassuring that therapeutic concentrations are reached in patients, toxicology may come into play when considering the purpose to monitor (and avoid) 
supratherapeutic (potentially toxic) concentrations. However, it is beyond the scope of this review to provide a full overview of all therapeutic drugs for which DBS sampling has been applied. The reader is referred to other, comprehensive reviews on this topic (e.g. Edelbroek et al., 2009, Li and Tse, 2010, Stolk and Edelbroek, 2010).

Metabolic screening programs based on DBS sampling aim at identifying disturbed balances in endogenous biomolecules, which may lead to toxic effects. A forensic application worth mentioning in this context is the "metabolic autopsy", which can be performed on DBS to screen for inherited metabolic disorders in cases of sudden infant death syndrome or sudden unexplained death syndrome (Chace et al., 2001). These DBS can either be obtained post mortem or can be those that were obtained at birth in cases where only later a metabolic disorder is suspected in deaths of previously unknown cause.

\section{Dried Blood Spots - Sources}

In developed countries, typically five DBS, each corresponding to about $80 \square 1$ of blood, are obtained by heel stick from the vast majority (>95\%) of newborns within the first 1-3 days of life. With the exception of the 'positive' cases, only a limited amount of this material is used for newborn screening programs, which primarily focus on inborn errors of metabolism. Thus, a substantial amount of valuable material is left behind. These remainders have proven to be a useful matrix for assessing certain exposures at birth. The prime aim of these assessments is to monitor prenatal exposure to toxic compounds capable of crossing the foetoplacental barrier. However, as in most cases no information is available with respect to breastfeeding, it needs to be remarked that postpartum exposure of the newborn via mother milk cannot be excluded. Moreover, when interpreting the results in the context of epidemiological studies, several potential sources of bias need to be kept in mind (Searles-Nielsen et al., 2008). First, although newborn screening is almost universal in developed countries, non-participation is 5 
unlikely to be random (e.g. infants may have died before DBS sampling or parents may have refused DBS sampling). Second, less (or no) material may be left from those newborns that tested positive in newborn screening programs. As analyses are typically performed on material that has been archived up to several years, contamination has to be excluded and analyses are limited to analytes with long-term stability in DBS. In addition, parameters potentially influencing the analytical result, such as haematocrit, blood volume spotted and site of punching (peripheral versus central) (Holub et al., 2006, O'Mara et al., 2011) have not been examined in many cases. Nevertheless, keeping these limitations in mind, newborn DBS can be valuable material for screening and may provide important retrospective information on the extent of exposure to a wide array of chemicals or elements. Given the fact that these early life exposures may be relevant to disease later in life, this information may not only result in a close follow-up of 'positively scored' newborns, but may also form the basis for intervention studies, targeting women at specific locations and/or belonging to specific (social) groups.

Apart from DBS sampling for newborn screening, more recently, this sampling technique has increasingly gained interest for its use in both animal and human studies. In humans (both adults and children), DBS are mostly obtained by finger prick. The resulting DBS, which may be directly applied from the finger onto the filter paper or via a precision capillary, are in general smaller than those obtained by heel stick. Advantages associated with the sampling itself primarily include its ease and its minimal invasiveness, facilitating sampling in remote areas and in paediatric studies by non-specialized individuals. Sampling from animals at specified time intervals after administration of a given drug is generally performed using microsampling devices (e.g. precision capillaries). The blood collected with these devices can be used to generate DBS, or it can be frozen, diluted in another solution or centrifuged to 6 
prepare plasma (Smith et al., 2011, Stokes et al., 2011). Applications include pharmaco- and toxicokinetics, TDM and clinical, forensic and environmental toxicology.

\section{Analysis of Therapeutic Drugs - Toxicokinetics}

Currently, many pharmaceutical companies undertake major efforts to implement DBS rather than classical plasma samples as starting material for bioanalytical measurements. These efforts are situated in the preclinical phase of the drug discovery process (e.g. toxicokinetics) as well as in later phases (pharmacokinetics and TDM). Here, we will primarily focus on the use of DBS for toxicokinetics, determining the relationship between systemic exposure of an animal to a compound and the harmful effects (toxicity) of this compound. A preliminary safety assessment can be derived from parameters such as bioavailability and dose proportionality, serving as a basis to decide which doses can be used in future studies.

From the point of view of animal welfare, DBS sampling conforms very well to the ' $3 \mathrm{R}$ principle (Replacement, Reduction, Refinement)' in toxico- and pharmacokinetic studies. The fact that finer needles can be used to obtain DBS and that there is no need to warm the animals prior to sampling, causes less distress to the animals. Besides this refinement, resulting in less animal burden, the implementation of DBS sampling also leads to a strong reduction in the number of animals needed in early drug discovery and preclinical studies. More specifically, DBS sampling requires less blood to be taken at each time point than is the case when analyses are performed using the 'classical' matrices plasma or serum. For the latter, the number of samples that can be collected per animal is limited by both ethical and physiological constraints. These constraints are greatly relieved by 'microsampling', resulting in the generation of DBS and allowing serial sampling from a strongly reduced amount of laboratory animals, including small rodents such as mice. This allows the replacement of composite pharmaco- or toxicokinetic profiles (obtained from different animals) by serial 
profiles (obtained within individual animals), which leads to higher data quality ( Clark et al., 2010, Turpin et al., 2010, Crawford et al., 2011). Apart from a large improvement in animal welfare, DBS sampling is also beneficial for the (pharmaceutical) companies involved. From a financial point of view, there is a serious reduction in costs associated with animal studies (including amount of test compound that should be available) and with sample handling. The latter includes both transportation costs to a bioanalytical facility and storage costs. Both transportation and storage are often facilitated, as experience has learned that stability, though requiring analyte-specific evaluation, is generally good. Thus, in many cases prolonged storage, even at ambient temperatures, is possible. Despite these many advantages, however, pharmaceutical companies initially somewhat restrained from utilizing DBS as an alternative to plasma or serum. Importantly, the use of DBS instead of plasma or serum necessitated a rethinking of bioanalytical procedures, particularly in the pre-analytical phase. This not only includes the selection of the filter paper card, but ideally also encompasses evaluation of the influence of spotting temperature, anticoagulant, the spotting device used, the volume spotted, the site of punching and the haematocrit, in addition to evaluation of the "on spot stability" and the effect of drying and storage conditions. Additionally, one should also dispose of means for detecting contamination, such as evaluation of blanks and/or incurred sample reanalysis (Spooner et al., 2009, Denniff and Spooner, 2010a, Denniff and Spooner, 2010b, Barfield and Wheller, 2011, Barfield et al., 2011, Timmerman et al., 2011). However, setting up new bioanalytical procedures is (was) not the main problem for the 'switch' from plasma to DBS. More important are regulatory constraints and the fact that plasma and serum have been used for decades as the gold standard, with all currently available toxico- and pharmacokinetic data having been obtained in these matrices. The latter implies that care should be taken, not only in evaluating how plasma concentrations correlate with blood or DBS concentrations, but also if and how capillary concentrations correlate with venous

8 
concentrations (Emmons and Rowland, 2010). This may be particularly relevant when evaluating early time points in kinetic experiments (Mohammed et al., 2010). Another factor to consider is the anticipated concentration: when in the low- or sub-ng/ml range, the limited amount of available material may impose analytical challenges that have to be dealt with. Recent improvements in analytical equipment, with primarily LC-MS/MS becoming more widespread available, have catalyzed progress in this field. Currently, major efforts are also being undertaken to render DBS analysis high-throughput-capable. Examples include the automated analysis of DBS, the on-line extraction and analysis of DBS ('direct elution') and direct desorption of DBS (e.g. Crawford et al., 2011, Déglon et al., 2011a). These new developments have recently been reviewed elsewhere (Déglon et al., 2011b, Abu-Rabie, 2011).

\section{Analysis of Drugs of Abuse}

Several publications and meeting abstracts demonstrate (or suggest) the potential of DBS for detecting exposure to drugs of abuse. Analytes measured include both legal drugs (scheduled drugs available on prescription) and illegal drugs. It needs to be mentioned, though, that some of these reports focus on the potential of determining these drugs for TDM (e.g. narcotic painkillers) or for newborn screening (e.g. monitoring exposure to cocaine), rather than for forensic purposes. In addition, several reports have demonstrated the possibility to identify drugs of abuse, as well as ethyl glucuronide, a marker for alcohol abuse, in blood spotted on different surfaces, rather than on filter paper. As in these cases the resulting blood spots are bloodstains rather than DBS, we do not consider these as true 'DBS applications' (Schütz et al., 2002, Fuller and Pisana, 2009, Winkler et al., 2011,). Overall, two sources of DBS can be distinguished for monitoring drugs of abuse: firstly DBS obtained from adults, where the application can be classified under 'forensic toxicology', and secondly DBS from newborns, 9 
where the aim is to assess exposure prior to birth. Owing to the low concentrations to be detected in minute amounts of material, LC-MS/MS has been the method of choice in the vast majority of applications, although also GC-MS has been applied in some cases (Table 1).

\section{Forensic Toxicology}

There is a substantial number of reports describing DBS applications for drugs of abuse (for an overview, see Table 1). Analytes of particular forensic interest that have been measured in DBS include benzodiazepines (alprazolam, clonazepam, diazepam, flunitrazepam, flurazepam, lorazepam, midazolam, nitrazepam, nordiazepam, oxazepam, phenazepam, temazepam), zolpidem, zopiclone, 3,4-methylenedioxymethamphetamine (MDMA), 3,4methylenedioxyamphetamine (MDA), 3,4-methylenedioxyethylamphetamine (MDEA), amphetamine, methamphetamine, cocaine, tetrahydrocannabinol (THC), opiates (6monoacetylmorphine, morphine, codeine, hydromorphone, hydrocodone, oxycodone, noroxycodone), tramadol, methadone, buprenorphine, fentanyl, ketamine and their respective metabolites and gamma-hydroxybutyric acid (GHB) (Henderson et al., 1993, Sosnoff et al., 1996, Henderson et al., 1997, Alfazil and Anderson, 2008, Garcia Boy et al., 2008, Moll et al., 2009, Clavijo et al., 2010, Havard et al., 2010, Ingels et al., 2010, Marin et al., 2010, Mercolini et al., 2010, Thomas et al., 2010, Clavijo et al., 2011a, Clavijo et al., 2011b, Hudson et al., 2011, Ingels

et al., 2011, Jantos and Skopp, 2011, Jantos et al., 2011a, Jantos et al., 2011b, Langel et al., 2011, Lauer et al., 2011). Also interesting from a forensic point of view is the potential to monitor alcohol abuse via the determination of ethylglucuronide and ethylsulfate or phosphatidylethanol in DBS (Faller et al., 2011, Jones et al., 2011, Redondo et al., 2011).

Although most reports have included patient samples, two important remarks need to be made. First, a substantial amount of these reports utilizes DBS prepared by pipetting venous blood 10 
onto a paper card (e.g. Garcia Boy et al., 2008, Ingels et al., 2010, Faller et al., 2011, Jantos and Skopp, 2011, Jantos et al., 2011b, Jones et al., 2011), with only a limited amount of reports describing the analysis of true capillary DBS (e.g. Sosnoff et al., 1996, Mercolini et al., 2010, Ingels et al., 2011). Although the latter can be obtained by using a precision capillary (Mercolini et al., 2010), our experience learned that this significantly complicates the procedure and ideally requires some training. Instead, direct application of the blood drop from the pricked fingertip onto the paper is generally found to be easy, also for a non-trained individual. However, as DBS obtained in this way do not represent a fixed volume, quantitative evaluation requires the analysis of DBS punches rather than of complete DBS. This brings us to the second remark. Analysis of (very) large spots, obtained from spotting up to $100 \square$, has been performed in a substantial number of publications (e.g. Alfazil and Anderson, 2008, Garcia Boy et al., 2008, Faller et al., 2011, Jantos and Skopp, 2011, Jantos et al., 2011b). These volumes are not easily obtained by finger prick; in our experience a spot applied directly from a pricked fingertip onto paper corresponds typically to less than $40 \square 1$ of blood. Moreover, the non-volumetric application also has the consequence that disks (typically 3,6 or $6.35 \mathrm{~mm}$ diameter) need to be punched from the paper, further reducing the amount of material available for analysis. Important to mention in this context is that the validation of methods starting from disk punches rather than from complete blood spots requires the evaluation of additional parameters such as punch location, haematocrit and volume spotted (Li and Tse, 2010, Ingels et al., 2011). Thus, although promising results have been obtained, suggesting more widespread applicability in forensic toxicology, true 'on-field' studies are needed for a substantial amount of compounds, in which DBS are obtained by a finger prick. Below we discuss more into detail two specific advantages associated with DBS sampling and the opportunities these offer for implementation in forensic toxicology: the ease of sampling (facilitating rapid sampling) and the stabilizing effect of DBS. 


\section{Ease of Sampling}

Although legislation in most countries does not (yet) allow non-medical staff to obtain DBS from someone else, the ease with which DBS can be taken renders it in principle possible to acquire a blood sample with a minimal loss of time. As this would imply that, at least in some instances, the sampling is done 'on-field', also care has to be taken to let the filter paper dry properly, as an analyte's stability may be impacted by the drying time and drying conditions. In such situations, the paper can be dried by e.g. putting it in a box or bag with desiccant, taking care that the blood spots do not come into contact with other surfaces. This approach of pro-active drying has already been applied in field studies where blood was sampled from wild birds (Trudeau et al., 2007).

Rapid sampling is particularly relevant in cases in which the half-life of a drug is short. Examples include cocaine, heroin (and its metabolite 6-monoacetylmorphine, 6-MAM) and GHB (Henderson et al., 1993, Sosnoff et al., 1996, Henderson et al., 1997, Alfazil and Anderson, 2008, Garcia Boy et al., 2008, Mercolini et al., 2010, Ingels et al., 2010, Ingels et al., 2011). Whereas cocaine intake can be demonstrated by virtue of its metabolite benzoylecgonine, heroin abuse cannot be simply deduced from the presence of its hydrolysis end-product, morphine (see also below). An even more difficult case is presented by GHB, which is also endogenously present and is rapidly cleared from the circulation. GHB or one of its precursors is sometimes used in cases of drug-facilitated sexual assault (DFSA). In these cases, there is most often readily a delay before the victim presents at the police station, thus sampling should be done as fast as possible (without needing to wait for a doctor to arrive). DBS sampling may be a good option in these cases.

The ease and speed of sampling also allows to investigate the epidemiology of drug abuse in a nightclub environment, where DBS could be obtained in "first aid" rooms (e.g. Wood et al., 2009). As in these cases informed consent needs to be obtained from individuals who are 
under the influence of drugs, this may pose bio-ethical issues, which can be dealt with via informed consent from a relative or via delayed informed consent.

DBS sampling in the context of DUID (driving under the influence of drugs) has only been evaluated to a limited extent (DRUID, 2011). Although for DUID testing, oral fluid has become the matrix of choice for both screening and confirmation in many countries, some controversy exists whether the obtained concentrations always closely mirror blood concentrations (supposedly best correlating with intoxication) and whether falsification by e.g. mouth washing may be possible (Bosker and Huestis, 2009, Huestis et al., 2011). DBS sampling does not suffer from these drawbacks and combines the advantages (relevance and reliability) of obtaining the ultimate specimen for determination of drug concentrations - i.e. blood - with an easy and rapid collection procedure by non-specialized staff. A key issue related to DBS sampling in this context is the exclusion of contamination.

For the follow-up of drug and alcohol addicts, DBS sampling may be useful to control abstinence from drugs and/or intake of substitution medication. Here, the use of DBS, though offering a more restricted window of detection, may offer an alternative for urine testing, which is now routinely used. Importantly, DBS sampling is gender neutral and is not hampered by privacy issues, which often lead to unsupervised sampling (and possibly adulteration) of urine. As there is also no need for medical staff, one may envisage a system in which unwittingly (former) addicts get a phone call at irregular time intervals and have to present themselves at a given centre to provide DBS under supervision. Moreover, given the higher prevalence of viral infections (e.g. hepatitis and HIV) in people with a history of intravenous drug abuse, the low biohazard risk posed by the resulting DBS is an additional important advantage. No manipulation of the blood is required (in contrast to e.g. the preparation of plasma, requiring centrifugation) and DBS can be transported via regular mail with no risk of breaking or leaking, thus minimizing the risk of transmitting blood-borne 
viruses and overcoming the need for taking special safety precautions (SCDHEC, 2011). In fact, viruses such as HIV-1 lose their infectivity as their envelope is disrupted upon drying, which has led to the use of DBS for routine HIV monitoring in screening and follow-up programs in developing countries (Johannessen, 2010).

Stabilizing Effect

Multiple publications have pointed out that DBS may have a stabilizing effect (e.g. Bowen et al., 2010, D'Arienzo et al., 2010). In a forensic context, this can be exemplified by several examples. First, the stabilizing effect on drugs having e.g. an ester function was demonstrated by the increased stability (reduced hydrolysis) of cocaine and 6-monoacetylmorphine (6-MAM, a metabolite of heroin) in DBS, as compared to whole blood (Henderson et al., 1993, Alfazil and Anderson, 2008, Garcia Boy et al., 2008). This is of particular importance as identification of 6MAM unequivocally demonstrates heroin use (whereas the presence of morphine alone doesn't). Secondly, DBS may also overcome the problem of ex vivo formation of a given compound. Whereas ex vivo formation of the club drug GHB in whole blood has been reported (Berankova et al., 2006, Zörntlein et al., 2011), prolonged storage of DBS at room temperature (up to 6 months) demonstrated no significant changes (Ingels et al., 2011). Similarly, whereas the presence of ethanol in blood may result in the ex vivo generation of phosphatidylethanol (1-palmitoyl-2-oleylsn-glycero-4-phosphoethanol) upon storage (Aradottir et al., 2004, Jones et al., 2011), this ex vivo formation does not take place in DBS (Jones et al., 2011). Thus, DBS sampling is able to counter a serious drawback associated with classical venous sampling, thereby increasing the trustworthiness of the result.

Apart from the aforementioned "metabolic autopsy" (Chace et al., 2001), which can be performed on DBS samples taken at autopsy, we found only one report in which analysis of DBS (obtained by spotting venous blood) from a post mortem sample has been described 14 
(Henderson et al., 1993). Although obviously for post mortem analysis there is no sampling advantage anymore, the increased stability of some analytes may still warrant DBS sampling. Yet, another difficulty is posed by the fact that post mortal blood may be lyzed or coagulated, leading to a different spread of the blood on the filter paper. Indeed, DBS generated from lyzed blood have been shown to differ ultrastructurally from those obtained from fresh blood (Cizdziel, 2007), which, dependent on the analyte to be measured, may (or may not) lead to skewing of the results (Cizdziel, 2007, Abu-Rabie and Spooner, 2010).

In the forensic toxicology laboratory, the use of DBS may also offer the possibility to preserve small amounts of sample in an economical way in 'closed cases', where all other evidence is to be discarded. When, for one reason or another, a case is to be reopened, there is at least some material left, potentially allowing targeted analysis. A similar approach has also been suggested for other biological matrices, such as urine (DuBey and Caplan, 1996). Obviously, a limitation is that only analytes can be detected that remain stable for an extended period of time (DuBey and Caplan, 1996).

\section{Newborn Screening}

Benzoylecgonine and cotinine, which are metabolites of cocaine and nicotine, respectively, have been determined in newborn DBS to assess the prevalence of the use of cocaine and tobacco products among childbearing women (Henderson et al., 1993, Sosnoff et al., 1996, Henderson et al., 1997, Spector et al., 2007). An inherent limitation here is that positive results will only indicate the mother's use of cocaine or tobacco near the time of delivery, thus only offering a limited view on the use during pregnancy. On the other hand, a factor likely extending the interval for detecting positive cases, is the immature liver function in newborns. Although immunological assays have been found to be a useful tool for initial screening of benzoylecgonine in DBS, confirmation is required using other techniques, such 15 
as mass spectrometry (GC-MS or LC-MS/MS) (Henderson et al., 1993, Sosnoff et al., 1996, Henderson et al., 1997). With respect to decision-making, any positive signal (above the limit of detection, LOD, or lower limit of quantification, LLOQ) may raise an alert. This implies that the lower the LOD or LLOQ of a given method, the higher the expected detection rate. Implementing a cut-off value in DBS testing of newborns for drugs of abuse may facilitate the inter-laboratory comparison of prevalences. While defining this decision limit, the potential error caused by the possible effect of e.g. varying haematocrit and volume spotted should be taken into account. However, as the cut-off would necessarily be above the LOD or LLOQ, the \% of false negatives will undoubtedly increase.

\section{Analysis of Environmental Contaminants}

Screening for environmental contaminants has been performed using DBS from both humans (primarily newborns) and animals. Examples of analytes that have been monitored include environmental pollutants such as benzene oxide (a metabolite of benzene, monitored via its adducts with haemoglobin) (Funk et al., 2008), organochlorine pesticides (Dua et al., 1996, Burse et al., 1997, Shlosberg et al., 2011b), perfluoroalkyl compounds (PFCs) (Spliethoff et al., 2008, Kato et al., 2009, Shlosberg et al., 2011b), polychlorinated biphenyls (PCBs) (Lu et al., 2011, Shlosberg et al., 2011b), polybrominated diphenyl esters (PBDEs) used as flame-retarding chemicals (Lu et al., 2011, Shlosberg et al., 2011b), perchlorate (Otero-Santos et al., 2009), heavy metals, as well as certain toxins. Although no published reports are available, yet, DBS have also been suggested to be useful for monitoring bisphenol A (Leonard et al., 2011).

An alternative, indirect way for assessing the exposure to a contaminant, is the monitoring of a biological activity directly influenced by this contaminant (via a so-called 'biomarker of effect'). Insecticides like organophosphates and carbamates are good candidates for this 
approach, as exposure can be assessed by virtue of their inhibition of cholinesterase activity. The first reports on the determination of cholinesterase activity in blood samples absorbed on filter paper readily date back to 1953 (Augustinsson and Heimburger, 1953, Heilbronn, 1953), a decade before Guthrie and Susi published on the detection of phenylalanine in newborn DBS (Guthrie and Susi, 1963). It needs to be remarked, though, that sensitivity is rather limited and ideally one should know an individual's enzyme activity prior to exposure, with only considerable intoxications resulting in a significant decrease in enzyme activity. Yet, multiple other publications have shown the potential to use (dried) blood and plasma spots for monitoring cholinesterase activity, primarily for occupational surveillance of exposed workers (Augustinsson and Holmstedt, 1965, Holmstedt and Oudart, 1966, Collombel and Perrot, 1970, Oudart and Holmstedt, 1970, Augustinsson et al., 1978, Eriksson and Faijersson, 1980, Rhyanen et al., 1984, Hilborn and Padilla, 2004, Quandt et al., 2010). Several of the DBS applications for monitoring environmental contaminants are discussed more into depth below.

\section{Newborn Screening}

The organochlorine dichlorodiphenyldichloroethylene (DDE, a metabolite of DDT) and the PFCs perfluorooctane sulphonate (PFOS) and perfluorooctanate (PFOA), as well as benzene oxide and perchlorate, have been detected in all evaluated newborns' DBS (Burse et al., 1997, Funk et al., 2008, Spliethoff et al., 2008, Kato et al., 2009, Otero-Santos et al., 2009), mirroring their general spread in ecosystems and their presence in virtually $100 \%$ of the adult population, including pregnant women (Woodruff et al., 2011). Interestingly, a sharp decline in perfluoroalkyl content in DBS from newborns after the year 2000, coinciding with the phasing-out of PFOS in the US, nicely demonstrates the utility of this approach for assessing temporal trends in exposure to environmental chemicals (Spliethoff et al., 2008). Newborn DBS have also been demonstrated to have the potential for monitoring exposure to 
supraphysiological levels of trace elements (e.g. lead), allowing the extraction of (semi)quantitative information (Langer et al., 2010). However, most of these studies have not been performed within the context of newborn screening and are therefore discussed in a separate paragraph.

\section{Biomonitoring of Animals}

Intoxication of animals with cholinesterase inhibitors (e.g. organophosphate and carbamate insecticides) may occur via ingestion (e.g. of exposed prey) or via dermal contact. Assessment of cholinesterase activity in DBS of avian species has been found sensitive enough to serve as a diagnostic tool for identifying exposure to cholinesterase-inhibiting pesticides. DBS sampling of animals allows the collection of samples at remote areas and in non-specialized centres, where no special equipment like a centrifuge is available and where proper storage of a blood sample is difficult (Trudeau et al., 2007).

A recent initiative in the context of monitoring exposure of animals to toxic substances, somewhat paralleling the efforts done for evaluating a newborn's exposure to environmental contaminants via DBS, is DABSE ("Database for avian blood spot examination") (Shlosberg et al., 2011a). This biomonitoring project aims at setting up reference values for exposure of wild birds to five groups of environmental contaminants: trace elements, organochlorine pesticides, PCBs, PFCs and PBDEs. Referral to the values within this database should help to pinpoint a possible cause in cases in which an individual bird or a bird population presents with a problem. A first application of this biomonitoring project was performed on griffon vultures, demonstrating detectable levels of several contaminants in DBS obtained from these birds (Shlosberg et al., 2011b).

Environmental health can also be assessed by monitoring the exposure of top predators, acting as sentinels. In coastal waters in the Gulf of Mexico, this approach has been used for 18 
monitoring the exposure of bottlenose dolphins to the marine algal biotoxins domoic acid and brevetoxins, respectively produced by members of the diatom genus Pseudo-nitzschia and by the dinoflagellate Karenia brevis (Twiner et al., 2011). Both biotoxins have been measured in DBS, obtained by spotting filter paper cards with $100 \square 1$ of blood, obtained from either exposed laboratory test animals (mice, rats or the fish species striped mullet) or from free-living dolphins (Fairey et al., 2001, Woofter et al., 2003, Woofter et al., 2005, Schwacke et al., 2010, Twiner et al., 2011). Toxin detection in DBS extracts has been performed using receptor-binding assays (Fairey et al., 2001) and radio immuno-assay (RIA, for brevetoxins) (Woofter et al., 2003) and, more recently, by competitive ELISA, either detecting brevetoxins and their metabolites, or domoic acid (Maucher and Ramsdell, 2005, Maucher et al., 2007). Ciguatoxins are another class of highly potent neurotoxins, sharing with brevetoxins the binding site 5 on the $\alpha$-subunit of voltage-gated sodium channels as effector site (Wang, 2008). Using a neuroblastoma cytotoxicity assay, ciguatoxins have been determined in DBS extracts from exposed mice (Bottein Dechraoui et al., 2005).

\section{Elemental Analysis}

Biomonitoring of toxic trace elements (metals and metalloids) in human blood has been applied for decades. Examples include lead, which exerts neurological toxicity, and arsenic, cadmium, mercury, chromium, copper, nickel and vanadium, all of which have distinct toxicity profiles. When aiming at (primarily) single-element analysis, analysis is usually performed by atomic absorption spectrometry (AAS), or more recently by (solid sampling) graphite furnace atomic absorption spectrometry ((SS-)GFAAS) (Verebey et al., 1991, Resano et al., 2007). Inductively coupled plasma mass spectrometry (ICP-MS) has been used for both single-element and for multi-element analysis, with more recent developments being 
laser ablation-ICP-(TOF-)MS and sector-field-ICP-MS (Cizdziel, 2007, Chaudhuri et al., 2009, Langer et al., 2010, Hsieh et al., 2011).

Considering the analysis of trace elements in DBS, most attention has been given to the determination of $\mathrm{Pb}$ in DBS obtained from children. Although the determination of venous $\mathrm{Pb}$ concentrations is considered the gold standard, venipuncture of infants and toddlers is impractical, may be traumatic for the children and in many countries is not widely accepted by the parents as a screening test for asymptomatic children (Shen et al., 2003). As children are particularly sensitive to $\mathrm{Pb}$ and in most countries $\mathrm{Pb}$ concentrations peak at approximately 2 years of age (American Academy of Pediatrics; Committee on Environmental Health, 2005, Chandran and Cataldo, 2010), a minimally invasive technique such as DBS sampling offers many advantages for obtaining a representative blood sample. Micro-sampling of blood for $\mathrm{Pb}$ determination in DBS was first reported in the early seventies (Delves, 1970, Cernik and Sayers, 1971). Although since then, many reports have been published on the determination of $\mathrm{Pb}$ in DBS, this approach has also been the subject of controversy, given the risk of contamination that may take place, as opposed to blood collection by venipuncture (Verebey et al., 1991, Stanton et al., 1999, Moyer et al., 1999, Verebey, 2000, Moyer et al., 2000, Stanton et al., 2000). Indeed, given the ubiquitous presence of $\mathrm{Pb}$ in the environment, special care has to be taken to avoid contamination at every step, from paper handling, sampling, and drying, over transport to analysis. More specifically, falsely elevated $\mathrm{Pb}$ concentrations may result from contamination by $\mathrm{Pb}$ present on the skin (thus necessitating suitable cleansing before sampling) and/or by improper paper handling (El-Hajjar et al., 2007, Moyer et al., 1999, Moyer et al., 2000). In contrast to a controlled clinical environment, in which the issue of contamination can be dealt with from sampling to analysis, one has to be aware that DBS sampling 'on-field', with less control on preanalytical variables, potentially suffers from an increased risk of contamination. Yet, especially in developing countries, where studies have 20 
shown that the threshold limit of $\mathrm{Pb}$ poisoning is exceeded in a large percentage of children (Shen et al., 1996, Ahamed and Siddiqui, 2007, Zhang et al., 2009), the lack of resources renders DBS sampling one of the most feasible ways for screening large populations (Shen et al., 2003). Sampling can be done on-site by a relatively untrained collector and samples can be sent by mail to an analytical laboratory. To correct for possibly inhomogeneous $\mathrm{Pb}$ distribution on the filter paper, analysis of 5 replicates (3.2-mm punches obtained from a single 50 - $\square 1$ blood spot) has been recommended by Resano and colleagues (Resano et al., 2007). However, in practice, blood spots often correspond to smaller blood volumes, which may limit the number of punches and/or may pose a problem when larger punches (e.g. 6 or $6.35 \mathrm{~mm}$ diameter) are to be analysed (Peck et al., 2009). The Pb concentrations determined in DBS have been shown to be independent from the volume spotted and from the site of punching (excluding the area near the perimeter, where concentrations are higher owing to a higher amount of red blood cells). Moreover, a good correlation was found between Pb concentrations in DBS and those in venous blood (El-Hajjar et al., 2007, Resano et al., 2007). DBS obtained from subjects with strongly deviating haematocrit values, however, may give rise to discordant results (El-Hajjar et al., 2007).

Apart from $\mathrm{Pb}$, also other toxic metals, as well as elements of clinical or forensic interest, have been determined (or have been shown to be detectable) in DBS, including $\mathrm{As}, \mathrm{Ba}, \mathrm{Be}, \mathrm{Bi}, \mathrm{Ca}, \mathrm{Cd}$, $\mathrm{Co}, \mathrm{Cr}, \mathrm{Cs}, \mathrm{Cu}, \mathrm{Fe}, \mathrm{Hg}, \mathrm{K}, \mathrm{Li}, \mathrm{Mg}, \mathrm{Mn}, \mathrm{Mo}, \mathrm{Na}, \mathrm{Ni}, \mathrm{P}, \mathrm{Rb}, \mathrm{S}, \mathrm{Sb}$, Se, Tl, V and Zn (Lombeck et al., 1989, Chaudhuri et al., 2009, Langer et al., 2010, Hsieh et al., 2011, Shlosberg et al., 2011b). Quantification of several of these elements may lead to the generation of an individual's "metallic profile", from which exposure to a certain contamination source may be deduced (Goullé et al., 2010). An important obstacle for fully quantitative analysis of a substantial amount of elements, however, is the variable contribution by the filter paper (both within and between lots) and possible contamination, 
requiring adequate control of blank filter paper. This implies the control of different lots of unexposed blank paper, directly from the manufacturer, as well as the control of paper ("internal blanks") at some distance from the DBS. Yet, still, one cannot fully exclude the scenario in which contamination within, but not near the DBS took place (Chaudhuri et al., 2009, Langer et al., 2010). The background values obtained from the controls can either be used for subtracting (possibly causing a negative bias) or can merely be used for evaluating the overall extent of contamination. Either way, replicate analysis of the same DBS (punch) and/or analysis of another DBS (punch) from positive cases is recommended to reduce the reporting of false positives (Cizdziel, 2007, Chaudhuri et al., 2009). In this respect, the technique of laser ablation ICP-TOFMS, providing a "line scan" with several data points per blank and per DBS, allows easy discrimination of potential random contamination (Cizdziel, 2007). Moreover, as reported by Cizdziel, the use of isotope ratio's determined by this technique may also allow to discriminate contamination extraneous to the blood sample (Cizdziel, 2007). To overcome the major problem of contamination encountered in elemental analysis of DBS and, at the same time, to account for possible variations in haematocrit and/or volume spotted, normalization may be another possible future improvement. This can be done using one or multiple elements, having a narrow physiological distribution and/or being (almost) absent in blank filter paper. As suggested by Langer et al., one such candidate could be potassium (Langer et al., 2010). Finally, it is important to mention that decision-making in the case of environmental pollution (including the analysis of trace elements) is somewhat distinct from that in the case of drugs of abuse. Whereas for the latter any positive signal (above the LOD, LLOQ or a certain cut-off) can raise an alert, positivity for the former can in many cases be considered as 'normal', with only levels exceeding a certain threshold warranting further follow-up. 


\section{Conclusion and Future Perspectives}

DBS sampling is being applied in a wide range of applications in toxicology, covering fields as toxicokinetics, epidemiology and environmental and forensic toxicology. The analytes measured in DBS include therapeutic drugs, drugs of abuse, environmental contaminants and (trace) elements. Among the advantages associated with DBS sampling, the ease of collecting a representative sample with minimal discomfort is of particular importance for its application in toxicology. This holds true for sampling of animals, newborns, children, but also for adults, considering the potential of DBS sampling at home or in the context of DFSA, DUID or the follow-up of drug addicts. The stabilizing effect of DBS, largely preventing both ex vivo degradation and de novo formation of analytes, is another significant advantage associated with this sampling technique, facilitating sample handling and transport and often allowing long-term storage of samples. Despite these -as well as other- important advantages, also some remarks should be made with respect to the use of DBS for toxicological purposes. A first remark is the issue of contamination, which primarily (but not only) is a problem in the field of elemental analysis. Although this issue can be largely dealt with in a tightly controlled environment, contamination can never be excluded, especially in the case of 'on-field' sampling. Given the bioanalyst's awareness of this problem, various avenues are being explored to increase the confidence one may have in a positive result. As mentioned above, these include e.g. the analysis of blank controls, the acquisition of multiple data points from a single spot or from replicate spots and/or attempts to normalize for e.g. haematocrit using one or multiple elements. A second remark is that for many analytes the influence of parameters such as haematocrit, volume spotted and site of punching has not been examined. Lack of knowledge about the influence of these (as well as other) parameters adds an additional, often neglected, factor of uncertainty to the reported analytical result. Thirdly, although promising results have been obtained in e.g. forensic toxicology, the approaches followed are often not 
fully compatible with the collection of true 'on-field' capillary blood samples, requiring more extensive validation. Apart from these points of attention, requiring more work to be done, it is our feeling that the largest contribution of DBS sampling in toxicology may lie in the field of drug development. There, its implementation of 'refinement' and 'reduction', allowing "small sampling of small animals" closely follows the $3 \mathrm{R}$ principle and is even accompanied by improved data quality. Also in (pre)clinical studies, the implementation of DBS sampling may be an incentive, e.g. by facilitating patient recruitment. As this evolution will evidently lead to a large amount of samples to be analyzed, current efforts are now being focused on automation and rapid, direct analyses of DBS.

\section{Acknowledgments}

We wish to acknowledge Dr. V. Stove for her critical reading of the manuscript.

Declaration of Interest

The author's affiliations are as shown on the cover page. This paper was prepared during the normal course of employment by Ghent University. The authors have sole responsibility for the writing and content of the paper. 


\section{References}

Abu-Rabie P. (2011). Direct analysis of DBS: emerging and desirable technologies. Bioanalysis 3:1675-1678.

Abu-Rabie P, Spooner N. (2010). Study to assess the effect of age of control human and animal blood on its suitability for use in quantitative bioanalytical DBS methods. Bioanalysis 2:1373-1384.

Ahamed M, Siddiqui MK. (2007). Environmental lead toxicity and nutritional factors. Clin Nutr 26:400-408.

Alfazil AA, Anderson RA. (2008). Stability of benzodiazepines and cocaine in blood spots stored on filter paper. J Anal Toxicol

32:511-515.

American Academy of Pediatrics; Committee on Environmental Health. (2005). Lead exposure in children: prevention, detection, and management. Pediatrics 116:1036-1046.

Aradottir S, Moller K, Alling C. (2004). Phosphatidylethanol formation and degradation in human and rat blood. Alcohol Alcsm 39:8-13.

Augustinsson KB, Eriksson H, Faijersson Y. (1978). A new approach to determining cholinesterase activities in samples of whole blood. Clin Chim Acta 89:239-252.

Augustinsson KB, Heimburger G. (1953). The determination of cholinesterase activity in blood samples absorbed on filter paper. Acta Physiol Scand 30:45-54.

Augustinsson KB, Holmstedt B. (1965). Determination of cholinesterase in blood samples dried on filter-paper and its practical application. Scand J Clin Lab Invest 17:573-583.

Bang I. (1913). Der Blutzucker. Wiesbaden, Germany.

Barfield M, Ahmad S, Busz M. (2011). GlaxoSmithKline's experience of incurred sample reanalysis for dried blood spot samples. Bioanalysis 3:1025-1030.

Barfield M, Wheller R. (2011). Use of Dried Plasma Spots in the Determination of Pharmacokinetics in Clinical Studies: Validation of a Quantitative Bioanalytical Method. Anal Chem 83:118-124.

Berankova K, Mutnanska K, Balikova M. (2006). Gamma-hydroxybutyric acid stability and formation in blood and urine. Forensic Sci Int 161:158-162.

Bodamer OA, Hoffmann GF, Lindner M. (2007). Expanded newborn screening in Europe 2007. J Inherit Metab Dis 30:439-444. Bosker WM, Huestis MA. (2009). Oral fluid testing for drugs of abuse. Clin Chem 55:1910-1931.

Bottein Dechraoui MY, Wang Z, Turquet J, Chinain M, Darius T, Cruchet P, Radwan FF, Dickey RW, Ramsdell JS. (2005).

Biomonitoring of ciguatoxin exposure in mice using blood collection cards. Toxicon 46:243-251.

Bowen CL, Hemberger MD, Kehler JR, Evans CA. (2010). Utility of dried blood spot sampling and storage for increased stability of photosensitive compounds. Bioanalysis 2:1823-1828.

Burse VW, DeGuzman MR, Korver MP, Najam AR, Williams CC, Hannon WH, Therrell BL. (1997). Preliminary investigation of the use of dried-blood spots for the assessment of in utero exposure to environmental pollutants. Biochem Mol Med 61:236-239.

Cernik AA, Sayers MH. (1971). Determination of lead in capillary blood using a paper punched disc atomic absorption technique. Application to the supervision of lead workers. Br J Ind Med 28:392-398.

Chace DH. (2009). Mass spectrometry in newborn and metabolic screening: historical perspective and future directions. J Mass Spectrom 44:163-170.

Chace DH, DiPerna JC, Mitchell BL, Sgroi B, Hofman LF, Naylor EW. (2001). Electrospray tandem mass spectrometry for analysis of acylcarnitines in dried postmortem blood specimens collected at autopsy from infants with unexplained cause of death. Clin Chem 47:1166-1182.

Chandran L, Cataldo R. (2010). Lead poisoning: basics and new developments. Pediatr Rev 31:399-405; quiz 406.

Chaudhuri SN, Butala SJ, Ball RW, Braniff CT. (2009). Pilot study for utilization of dried blood spots for screening of lead, mercury and cadmium in newborns. J Expo Sci Environ Epidemiol 19:298-316.

Cizdziel JV. (2007). Determination of lead in blood by laser ablation ICP-TOF-MS analysis of blood spotted and dried on filter paper: a feasibility study. Anal Bioanal Chem 388:603-611.

Clark GT, Haynes JJ, Bayliss MA, Burrows L. (2010). Utilization of DBS within drug discovery: development of a serial microsampling pharmacokinetic study in mice. Bioanalysis 2:1477-1488.

Clavijo CF, Hoffman KL, Thomas JJ, Carvalho B, Chu LF, Drover DR, Hammer GB, Christians U, Galinkin JL. (2011a). A sensitive assay for the quantification of morphine and its active metabolites in human plasma and dried blood spots using highperformance liquid chromatography-tandem mass spectrometry. Anal Bioanal Chem 400:715-728.

Clavijo CF, Thomas JJ, Cromie M, Schniedewind B, Hoffman KL, Christians U, Galinkin JL. (2011b). A low blood volume LC-MS/MS assay for the quantification of fentanyl and its major metabolites norfentanyl and despropionyl fentanyl in children. J Sep Sci. doi:10.1002/jssc.201100422.

Clavijo CF, Thomas JJ, Hammer GB, Christians U, Galinkin JL (2010). A sensitive LC-MS/MS Assay for Quantification of Methadone and Its Metabolites in Dried Blood Spots. Proceedings of the Annual Meeting of the American Society of Anesthesiologists (ASA). San Diego, CA.

Collombel C, Perrot L. (1970). [Determination of cholinesterase activity in whole blood obtained by capillary puncture and deposited on filter paper. Application to the detection of poisoning by organophosphorus insecticides]. Eur J Toxicol 3:368-372. 
Crawford E, Gordon J, Wu JT, Musselman B, Liu R, Yu S. (2011). Direct analysis in real time coupled with dried spot sampling for bioanalysis in a drug-discovery setting. Bioanalysis 3:1217-1226.

25 
D'Arienzo CJ, Ji QC, Discenza L, Cornelius G, Hynes J, Cornelius L, Santella JB, Olah T. (2010). DBS sampling can be used to stabilize prodrugs in drug discovery rodent studies without the addition of esterase inhibitors. Bioanalysis 2:1415-1422.

Déglon J, Thomas A, Daali Y, Lauer E, Samer C, Desmeules J, Dayer P, Mangin P, Staub C. (2011a). Automated system for on-line desorption of dried blood spots applied to LC/MS/MS pharmacokinetic study of flurbiprofen and its metabolite. J Pharm Biomed Anal 54:359-367.

Déglon J, Thomas A, Mangin P, Staub C. (2011b). Direct analysis of dried blood spots coupled with mass spectrometry: concepts and biomedical applications. Anal Bioanal Chem doi:10.1007/s00216-011-5161-6.

Delves HT. (1970). A micro-sampling method for the rapid determination of lead in blood by atomic-absorption spectrophotometry. Analyst 95:431-438.

Denniff P, Spooner N. (2010a). The effect of hematocrit on assay bias when using DBS samples for the quantitative bioanalysis of drugs. Bioanalysis 2:1385-1395.

Denniff P, Spooner N. (2010b). Effect of storage conditions on the weight and appearance of dried blood spot samples on various cellulose-based substrates. Bioanalysis 2:1817-1822.

DRUID (2011). DRUID (Driving under the Influence of Drugs, Alcohol and Medicines), Work Package 1: Experimental Studies, Effects of stimulant drugs on actual and simulated driving. [Online] Available at: http://www.druid-

project.eu/cln_031/nn_107534/sid_7A536E257F91FDEEACFADC69D72378AA/nsc_true/Druid/EN/deliverales-list/deliverableslist-node.html?_nnn=true. Accessed on September 8th, 2011

Dua VK, Pant CS, Sharma VP, Pathak GK. (1996). Determination of HCH and DDT in finger-prick whole blood dried on filter paper and its field application for monitoring concentrations in blood. Bull Environ Contam Toxicol 56:50-57.

DuBey IS, Caplan YH. (1996). The storage of forensic urine drug specimens as dry stains: recovery and stability. J Forensic Sci 41:845-850.

Edelbroek PM, van der Heijden J, Stolk LM. (2009). Dried blood spot methods in therapeutic drug monitoring: methods, assays, and pitfalls. Ther Drug Monit 31:327-336.

El-Hajjar DF, Swanson KH, Landmark JD, Stickle DF. (2007). Validation of use of annular once-punched filter paper bloodspot samples for repeat lead testing. Clin Chim Acta 377:179-184.

Emmons G, Rowland M. (2010). Pharmacokinetic considerations as to when to use dried blood spot sampling. Bioanalysis 2:1791-1796.

Eriksson H, Faijersson Y. (1980). A reliable way of estimating cholinesterases from whole blood in the presence of anticholinesterases. Clin Chim Acta 100:165-171.

Fairey ER, Shuart NG, Busman M, Moeller PD, Ramsdell JS. (2001). Biomonitoring brevetoxin exposure in mammals using blood collection cards. Environ Health Perspect 109:717-720.

Faller A, Richter B, Kluge M, Koenig P, Seitz HK, Thierauf A, Gnann H, Winkler M, Mattern R, Skopp G. (2011). LC-MS/MS analysis of phosphatidylethanol in dried blood spots versus conventional blood specimens. Anal Bioanal Chem 401:1163-1166.

Fuller DC, Pisana P (2009). A Preliminary Investigation into Retrospective Calculation of In-Vivo Drug Concentrations in Dried Crime Scene Blood. Proceedings of the 39th Annual Meeting of the Society of Forensic Toxicologists (SOFT). Oklahoma City, OK. Funk WE, Waidyanatha S, Chaing SH, Rappaport SM. (2008). Hemoglobin adducts of benzene oxide in neonatal and adult dried blood spots. Cancer Epidemiol Biomarkers Prev 17:1896-1901.

Garcia Boy R, Henseler J, Mattern R, Skopp G. (2008). Determination of morphine and 6-acetylmorphine in blood with use of dried blood spots. Ther Drug Monit 30:733-739.

Garg U, Dasouki M. (2006). Expanded newborn screening of inherited metabolic disorders by tandem mass spectrometry: clinical and laboratory aspects. Clin Biochem 39:315-332.

Goullé JP, Saussereau E, Mahieu L, Bouige D, Guerbet M, Lacroix C. (2010). Le profil métallique: un nouveau concept médical. Rev Med Interne 31:128-134.

Guthrie R, Susi A. (1963). A Simple Phenylalanine Method for Detecting Phenylketonuria in Large Populations of Newborn Infants. Pediatrics 32:338-343.

Havard G, Théberge M-C, Boudreau N, Lévesque A, Massé R (2010). Development and Validation of a Dried Blood Spot Assay for the Determination of Midazolam in Human Whole Blood by LCMSMS. Proceedings of the American Association of

Pharmaceutical Scientists (AAPS) - Pharmaceutical Sciences World Congress. New Orleans, LA.

Heilbronn E. (1953). An electrometric method for the determination of cholinesterase activity. III. Cholinesterase activity in blood spots on filter paper. Scand J Clin Lab Invest 5:308-311.

Henderson LO, Powell MK, Hannon WH, Bernert JT, Jr., Pass KA, Fernhoff P, Ferre CD, Martin L, Franko E, Rochat RW, Brantley $M D$, Sampson E. (1997). An evaluation of the use of dried blood spots from newborn screening for monitoring the prevalence of cocaine use among childbearing women. Biochem Mol Med 61:143-151.

Henderson LO, Powell MK, Hannon WH, Miller BB, Martin ML, Hanzlick RL, Vroon D, Sexson WR. (1993). Radioimmunoassay screening of dried blood spot materials for benzoylecgonine. J Anal Toxicol 17:42-47.

Hilborn ED, Padilla S. (2004). A dried blood spot method to evaluate cholinesterase activity in young children. Arch Environ Health 59:467-470. 
Holmstedt B, Oudart JL. (1966). [Determination of plasma cholinesterase activity by means of a paper test]. Bull Soc Pathol Exot Filiales 59:411-426. 
Holub M, Tuschl K, Ratschmann R, Strnadova KA, Muhl A, Heinze G, Sperl W, Bodamer OA. (2006). Influence of hematocrit and localisation of punch in dried blood spots on levels of amino acids and acylcarnitines measured by tandem mass spectrometry. Clin Chim Acta 373:27-31.

Hsieh HF, Chang WS, Hsieh YK, Wang CF. (2011). Using dried-droplet laser ablation inductively coupled plasma mass spectrometry to quantify multiple elements in whole blood. Anal Chim Acta 699:6-10.

Hudson W, Yong B, Boguszewski P (2011). Analysis of Clozapine, Nortriptyline, Paroxetine and Zolpidem Using Dried Blood Spots. [Online] Available at: http://www.chem.agilent.com/Library/applications/5990-8033EN.pdf. Accessed on November, 25th, 2011.

Huestis MA, Verstraete A, Kwong TC, Morland J, Vincent MJ, de la Torre R. (2011). Oral fluid testing: promises and pitfalls. Clin Chem 57:805-810.

Ingels AS, De Paepe P, Anseeuw K, Van Sassenbroeck DK, Neels H, Lambert WE, Stove CP. (2011). Dried blood spot punches for confirmation of suspected gamma-hydroxybutyric acid intoxications: validation of an optimized GC-MS procedure. Bioanalysis 3:2271-2281.

Ingels AS, Lambert WE, Stove CP. (2010). Determination of gamma-hydroxybutyric acid in dried blood spots using a simple GCMS method with direct "on spot" derivatization. Anal Bioanal Chem 398:2173-2182.

Jantos R, Schumacher M, Skopp G (2011a). Comparison of Opioid Analysis in Whole Blood and Dried Blood Spots. Proceedings of the 49th Annual Meeting of The International Association of Forensic Toxicologists (TIAFT). San Francisco, CA.

Jantos R, Skopp G. (2011). Comparison of drug analysis in whole blood and dried blood spots. Toxichem Krimtech 78:268-275.

Jantos R, Veldstra JL, Mattern R, Brookhuis KA, Skopp G. (2011b). Analysis of 3,4-methylenedioxymetamphetamine: whole blood versus dried blood spots. J Anal Toxicol 35:269-273.

Johannessen A. (2010). Dried blood spots in HIV monitoring: applications in resource-limited settings. Bioanalysis 2:1893-1908. Jones J, Jones M, Plate C, Lewis D. (2011). The detection of 1-palmitoyl-2-oleoyl-sn-glycero-3-phosphoethanol in human dried blood spots. Anal Methods-Uk 3:1101-1106.

Kato K, Wanigatunga AA, Needham LL, Calafat AM. (2009). Analysis of blood spots for polyfluoroalkyl chemicals. Anal Chim Acta 656:51-55.

Langel K, Uusivirta H, Ariniemi K, Lillsunde P (2011). Analysis of Drugs of Abuse by GC-MS in Dried Blood Spot Sample Matrix. Proceedings of the 49th Annual Meeting of The International Association of Forensic Toxicologists (TIAFT). San Francisco, CA. Langer EK, Johnson KJ, Shafer MM, Gorski P, Overdier J, Musselman J, Ross JA. (2010). Characterization of the elemental composition of newborn blood spots using sector-field inductively coupled plasma-mass spectrometry. J Expo Sci Environ Epidemiol 21:355-364.

Lauer E, Déglon J, Versace F, Thomas A, Mangin P, Staub C (2011). Target Screening of Drugs from Dried Blood Spot Samples Based on LC-MS/MS and On-Line Desorption. Proceedings of the 49th Annual Meeting of The International Association of Forensic Toxicologists (TIAFT). San Francisco, CA.

Leonard S, Moshin J, Wittrig R, Serreiber A (2011). Quantitation of Bisphenol A in Dried Blood Spots using liquid chromatography tandem mass spectrometry. Proceedings of the American Association for Clinical Chemistry (AACC) Annual Meeting. Atlanta, GA. Li W, Tse FL. (2010). Dried blood spot sampling in combination with LC-MS/MS for quantitative analysis of small molecules. Biomed Chromatogr 24:49-65.

Lombeck I, Papadaki-Papandreou O, Kamiri F, Laryea MD, Jiang YF, Leitzmann P. (1989). A screening method for the evaluation of selenium status. J Trace Elem Electrolytes Health Dis 3:175-178.

Lu D, Wang D, Barley F, Ramage B, She J (2011). Determination of polychlorinated biphenyls and polybrominated diphenyl ethers in dried blood spots and very low volume blood samples. Proceedings of Dioxin 2011. Brussels, Belgium.

Marin LJ, Tyrrel-Pawlowic CA, Moroney EC, Coopersmith BI, Shet MS (2010). Comparative analysis of buprenorphine and oxycodone in human dried blood spots (DBS) using LC/MS/MS. Proceedings of the American Association of Pharmaceutical Scientists (AAPS) - Pharmaceutical Sciences World Congress. New Orleans, LA.

Maucher JM, Briggs L, Podmore C, Ramsdell JS. (2007). Optimization of blood collection card method/enzyme-linked immunoassay for monitoring exposure of bottlenose dolphin to brevetoxin-producing red tides. Environ Sci Technol 41:563-567. Maucher JM, Ramsdell JS. (2005). Ultrasensitive detection of domoic acid in mouse blood by competitive ELISA using blood collection cards. Toxicon 45:607-613.

Mercolini L, Mandrioli R, Gerra G, Raggi MA. (2010). Analysis of cocaine and two metabolites in dried blood spots by liquid chromatography with fluorescence detection: a novel test for cocaine and alcohol intake. J Chromatogr A 1217:7242-7248. Mohammed BS, Cameron GA, Cameron L, Hawksworth GH, Helms PJ, McLay JS. (2010). Can finger-prick sampling replace venous sampling to determine the pharmacokinetic profile of oral paracetamol? Br J Clin Pharmacol 70:52-56.

Moll V, Clavijo C, Cohen M, Christians U, Galinkin J (2009). A Analytical Method To Determine Ketamine and Norketamine Levels in Dried Blood Spots. Proceedings of the Annual Meeting of the American Society of Anesthesiologists (ASA). New Orleans, LA. 
Moyer TP, Nixon DE, Ash OK. (2000). Filter paper-collected blood lead testing in children - Response. Clin Chem 46:1026-1028. Moyer TP, Nixon DN, Ash KO. (1999). Filter paper lead testing. Clin Chem 45:2055-2056.

O'Mara M, Hudson-Curtis B, Olson K, Yueh Y, Dunn J, Spooner N. (2011). The effect of hematocrit and punch location on assay bias during quantitative bioanalysis of dried blood spot samples. Bioanalysis 3:2335-2347.

Otero-Santos SM, Delinsky AD, Valentin-Blasini L, Schiffer J, Blount BC. (2009). Analysis of perchlorate in dried blood spots using ion chromatography and tandem mass spectrometry. Anal Chem 81:1931-1936.

Oudart JL, Holmstedt B. (1970). Determination of plasma cholinesterase activity by means of a test paper and its use in the field. Arch Toxikol 27:1-12.

Peck HR, Timko DM, Landmark JD, Stickle DF. (2009). A survey of apparent blood volumes and sample geometries among filter paper bloodspot samples submitted for lead screening. Clin Chim Acta 400:103-106.

Quandt SA, Chen H, Grzywacz JG, Vallejos QM, Galvan L, Arcury TA. (2010). Cholinesterase depression and its association with pesticide exposure across the agricultural season among Latino farmworkers in North Carolina. Environ Health Perspect 118:635-639.

Redondo AH, Weinmann W, König S (2011). Detection of Ethylglucuronide and Ethylsulfate in Dried Blood Spots. Proceedings of the 49th Annual Meeting of The International Association of Forensic Toxicologists (TIAFT). San Francisco, CA.

Resano M, Rello L, Garcia-Ruiz E, Belarra MA. (2007). Minimally-invasive filter paper test in combination with solid samplinggraphite furnace atomic absorption spectrometry for Pb determination in whole blood. J Anal At Spectrom 22:1250-1259.

Rhyanen R, Liesivuori J, Narhi M, Puhakainen E, Hanninen O. (1984). Blood cholinesterase activities of flower garden workers after exposure to organophosphates. Bull Environ Contam Toxicol 32:251-258.

SCDHEC (2011). Transporting and Shipping Infectious Substances A and B. [Online] Available at:

http://www.scdhec.gov/health/lab/docs/labeling.pdf. Accessed on November 23rd, 2011.

Schütz H, Gotta JC, Erdmann F, Risse M, Weiler G. (2002). Simultaneous screening and detection of drugs in small blood samples and bloodstains. Forensic Sci Int 126:191-196.

Schwacke LH, Twiner MJ, De Guise S, Balmer BC, Wells RS, Townsend FI, Rotstein DC, Varela RA, Hansen LJ, Zolman ES, Spradlin TR, Levin M, Leibrecht H, Wang Z, Rowles TK. (2010). Eosinophilia and biotoxin exposure in bottlenose dolphins (Tursiops truncatus) from a coastal area impacted by repeated mortality events. Environ Res 110:548-555.

Searles-Nielsen S, Mueller BA, De Roos AJ, Checkoway H. (2008). Newborn screening archives as a specimen source for epidemiologic studies: Feasibility and potential for bias. Ann Epidemiol 18:58-64.

Seashore MR, Seashore CJ. (2005). Newborn screening and the pediatric practitioner. Semin Perinatol 29:182-188.

Shen X, Rosen JF, Guo D, Wu S. (1996). Childhood lead poisoning in China. Sci Total Environ 181:101-109.

Shen XM, Zhang YW, Wu SH, Yan CH, Ying JM, Li RQ. (2003). Applicability of a filter paper method to measure blood lead levels in large populations of Chinese children. Clin Chim Acta 328:99-104.

Shlosberg A, Rumbeiha WK, Lublin A, Kannan K. (2011a). A database of avian blood spot examinations for exposure of wild birds to environmental toxicants: the DABSE biomonitoring project. J Environ Monit 13:1547-1558.

Shlosberg A, Wu Q, Rumbeiha WK, Lehner A, Cuneah O, King R, Hatzofe O, Kannan K, Johnson M. (2011b). Examination of Eurasian Griffon Vultures (Gyps fulvus fulvus) in Israel for Exposure to Environmental Toxicants Using Dried Blood Spots. Arch Environ Contam Toxicol doi:10.1007/s00244-011-9709-4.

Smith C, Skyes A, Robinson S, Thomas E. (2011). Evaluation of blood microsampling techniques and sampling sites for the analysis of drugs by HPLC-MS. Bioanalysis 3:145-156.

Sosnoff CS, Ann Q, Bernert JT, Jr., Powell MK, Miller BB, Henderson LO, Hannon WH, Fernhoff P, Sampson EJ. (1996). Analysis of benzoylecgonine in dried blood spots by liquid chromatography--atmospheric pressure chemical ionization tandem mass spectrometry. J Anal Toxicol 20:179-184.

Spector LG, Hecht SS, Ognjanovic S, Carmella SG, Ross JA. (2007). Detection of cotinine in newborn dried blood spots. Cancer Epidemiol Biomarkers Prev 16:1902-1905.

Spliethoff HM, Tao L, Shaver SM, Aldous KM, Pass KA, Kannan K, Eadon GA. (2008). Use of Newborn Screening Program blood spots for exposure assessment: Declining levels of perfluorinated compounds in New York State infants. Environ Sci Technol 42:5361-5367.

Spooner N, Lad R, Barfield M. (2009). Dried Blood Spots as a Sample Collection Technique for the Determination of Pharmacokinetics in Clinical Studies: Considerations for the Validation of a Quantitative Bioanalytical Method. Anal Chem 81:1557-1563.

Stanton N, Maney J, Jones R. (2000). More on filter paper lead testing. Clin Chem 46:1028-1029.

Stanton NV, Maney JM, Jones R. (1999). Evaluation of filter paper blood lead methods: results of a pilot proficiency testing program. Clin Chem 45:2229-2235.

Stokes AH, Moose TA, Parry SP, Barfield M, Lovatt CA, Dopson WJ, Melich D, Overvold CR, Gade SD, Spooner N. (2011). Determination of drug concentrations using dried blood spots: investigation of blood sampling and collection techniques in Crl:CD(SD) rats. Lab Anim 45:109-113. 
Stolk LM, Edelbroek PM (2010). Characteristics of new TDM assays, described in literature, based on dried blood spot methods. [Online] Available at: http://www.iatdmct.org/images/File/Update\%20review\%20TDM14072010.pdf. Accessed on August 30th, 2011. 
Thomas A, Déglon J, Steimer T, Mangin P, Daali Y, Staub C. (2010). On-line desorption of dried blood spots coupled to hydrophilic interaction/reversed-phase LC/MS/MS system for the simultaneous analysis of drugs and their polar metabolites. J Sep Sci 33:873-879.

Timmerman P, White S, Globig S, Ludtke S, Brunet L, Smeraglia J. (2011). EBF recommendation on the validation of bioanalytical methods for dried blood spots. Bioanalysis 3:1567-1575.

Trudeau S, Mineau P, Cartier GS, Fitzgerald G, Wilson L, Wheler C, Knopper LD. (2007). Using dried blood spots stored on filter paper to measure cholinesterase activity in wild avian species. Biomarkers 12:145-154.

Turpin PE, Burnett JE, Goodwin L, Foster A, Barfield M. (2010). Application of the DBS methodology to a toxicokinetic study in rats and transferability of analysis between bioanalytical laboratories. Bioanalysis 2:1489-1499.

Twiner MJ, Fire S, Schwacke L, Davidson L, Wang Z, Morton S, Roth S, Balmer B, Rowles TK, Wells RS. (2011). Concurrent exposure of bottlenose dolphins (Tursiops truncatus) to multiple algal toxins in Sarasota Bay, Florida, USA. PLoS One 6:e17394. Verebey K. (2000). Filter paper-collected blood lead testing in children. Clin Chem 46:1024-1028.

Verebey K, Eng YM, Davidow B, Ramon A. (1991). Rapid, sensitive micro blood lead analysis: a mass screening technique for lead poisoning. J Anal Toxicol 15:237-240.

Wang DZ. (2008). Neurotoxins from marine dinoflagellates: a brief review. Mar Drugs 6:349-371.

Watson MS, Mann MY, Lloyd-Puryear MA, Rinaldo P, Rodney Howell R. (2006). Newborn screening: Toward a uniform screening panel and system - Executive summary. Pediatrics 117:S296-S307.

Winkler M, Kaufmann E, Thoma D, Thierauf A, Weinmann W, Skopp G, Alt A. (2011). Detection of ethyl glucuronide in blood spotted on different surfaces. Forensic Sci Int 210:243-246.

Wood DM, Nicolaou M, Dargan PI. (2009). Epidemiology of recreational drug toxicity in a nightclub environment. Subst Use Misuse 44:1495-1502.

Woodruff TJ, Zota AR, Schwartz JM. (2011). Environmental chemicals in pregnant women in the United States: NHANES 20032004. Environ Health Perspect 119:878-885.

Woofter R, Dechraoui MY, Garthwaite I, Towers NR, Gordon CJ, Cordova J, Ramsdell JS. (2003). Measurement of brevetoxin levels by radioimmunoassay of blood collection cards after acute, long-term, and low-dose exposure in mice. Environ Health Perspect 111:1595-1600.

Woofter RT, Brendtro K, Ramsdell JS. (2005). Uptake and elimination of brevetoxin in blood of striped mullet (Mugil cephalus) after aqueous exposure to Karenia brevis. Environ Health Perspect 113:11-16.

Zhang SM, Dai YH, Xie XH, Fan ZY, Tan ZW, Zhang YF. (2009). Surveillance of childhood blood lead levels in 14 cities of China in 2004-2006. Biomed Environ Sci 22:288-296.

Zörntlein SW, Kopp A, Becker J, Kaufmann TJ, Rohrich J, Urban R. (2011). In vitro production of GHB in blood and serum samples under various storage conditions. Forensic Sci Int doi:10.1016/j.forsciint.2011.07.030.

\begin{tabular}{ll}
$\begin{array}{l}\text { Analyte } \\
\text { (MARKERS OF) DRUGS OF ABUSE } \\
\text { Amphetamine }\end{array}$ & \multicolumn{1}{c}{ Technique } \\
MC-MS/MS GC-MS \\
MDMA, MDA & LC-MS/MS GC-MS \\
MDEA & LC-MS/MS \\
Methamphetamine & LC-MS/MS GC-MS \\
Cocaine, benzoylecgonine & RIA, GC-MS \\
and other metabolites & RIA, LC-MS \\
& LC-FLUO \\
& LC-MS/MS \\
& GC-MS \\
Benzodiazepines & LC-MS/MS \\
& GC-MS \\
Zolpidem & LC-MS/MS \\
Zopiclone & LC-MS/MS GC-MS \\
Ketamine and norketamine & LC-MS/MS \\
Gamma-hydroxybutyric acid & GC-MS \\
Opiates and metabolites & LC-MS/MS \\
& GC-MS
\end{tabular}

\section{Selected References}

Jantos and Skopp, 2011; Lauer et al., 2011

Langel et al., 2011

Jantos and Skopp, 2011; Jantos et al., 2011b; Lauer et al., 2011

Langel et al., 2011

Lauer et al., 2011

Lauer et al., 2011

Langel et al., 2011

Henderson et al., 1993

Henderson et al., 1997

Mercolini et al., 2010

Sosnoff et al., 1996; Alfazil and Anderson, 2008; Lauer et al., 2011

Langel et al., 2011

Alfazil and Anderson, 2008; Havard et al., 2010; Thomas et al, 2010; Jantos and Skopp, 2011; Lauer et al., 2011

Langel et al., 2011

Hudson et al., 2011; Lauer et al., 2011

Jantos and Skopp, 2011; Lauer et al., 2011

Langel et al., 2011

Moll et al., 2009

Ingels et al., 2010; Ingels et al.,2011

Garcia Boy et al., 2008; Thomas et al., 2010; Marin et al., 2010; Clavijo et al., 2011a;

Jantos et al., 2011a; Lauer et al., 2011

Langel et al., 2011 


\begin{tabular}{|c|c|c|c|}
\hline \multicolumn{2}{|c|}{$\begin{array}{l}\text { Buprenorphine and } \\
\text { metabolites }\end{array}$} & LC-MS/MS GC-MS & $\begin{array}{l}\text { Thomas et al., 2010; Marin } \\
\text { Langel et al., } 2011\end{array}$ \\
\hline \multicolumn{2}{|c|}{ Methadone and metabolites } & LC-MS/MS GC-MS & $\begin{array}{l}\text { Clavijo et al., 2010, Lauer e } \\
\text { Langel et al., } 2011\end{array}$ \\
\hline \multicolumn{2}{|c|}{ Fentanyl and metabolites } & LC-MS/MS & Clavijo et al., 2011b; Jantos \\
\hline \multicolumn{2}{|c|}{ Tramadol } & GC-MS & Langel et al., 2011 \\
\hline \multicolumn{2}{|c|}{$\begin{array}{l}\text { Tetrahydrocannabinol and } \\
\text { metabolites }\end{array}$} & LC-MS/MS GC-MS & $\begin{array}{l}\text { Thomas et al., } 2010 \\
\text { Langel et al., } 2011\end{array}$ \\
\hline \multicolumn{2}{|c|}{ Cotinine } & GC-MS & Spector et al., 2007 \\
\hline \multicolumn{2}{|c|}{$\begin{array}{l}\text { Ethylglucuronide - } \\
\text { ethylsulfate }\end{array}$} & LC-MS/MS & Redondo et al., 2011 \\
\hline \multicolumn{2}{|c|}{ Phosphatidylethanol } & LC-MS/MS & Faller et al., 2011; Jones et \\
\hline \multicolumn{4}{|c|}{ ENVIRONMENTAL CONTAMINANTS } \\
\hline \multicolumn{2}{|c|}{ Benzene oxide } & GC-MS & Funk et al., 2008 \\
\hline \multirow{2}{*}{\multicolumn{2}{|c|}{ Organochlorine pesticides }} & GC-ECD & Dua et al., 1996; Burse et a \\
\hline & & GC-HRMS & Shlosberg et al., 2011b \\
\hline \multicolumn{2}{|c|}{ Perfluoroalkyl compounds } & LC-MS/MS & Spliethoff et al., 2008; Katc \\
\hline \multicolumn{2}{|c|}{ Polychlorinated biphenyls } & GC-HRMS & Shlosberg et al., 2011b; Lu \\
\hline \multicolumn{2}{|c|}{$\begin{array}{l}\text { Polybrominated diphenyl } \\
\text { esters }\end{array}$} & GC-HRMS & Shlosberg et al., 2011b; Lu \\
\hline \multicolumn{2}{|c|}{ Perchlorate } & IC-MS/MS & Otero-Santos et al., 2009 \\
\hline \multicolumn{2}{|c|}{ Bisphenol A } & LC-MS/MS & Leonard et al., 2011 \\
\hline \multicolumn{2}{|c|}{ Cholinesterase Inhibitors } & $\begin{array}{l}\text { Cholinesterase } \\
\text { activity } \\
\text { measurement }\end{array}$ & $\begin{array}{l}\text { Heilbronn, 1953; Augustins } \\
\text { 1965; Holmstedt and Ouda } \\
\text { 1970; Augustinsson et al., } \\
\text { Hilborn and Padilla, 2004; }\end{array}$ \\
\hline \multicolumn{4}{|l|}{ BIOTOXINS } \\
\hline \multirow{4}{*}{$\begin{array}{l}\text { Domoic acid } \\
\text { Brevetoxins }\end{array}$} & C-ELISA & \multicolumn{2}{|c|}{ Maucher and Ramsdell, 2005} \\
\hline & R-binding assay & \multicolumn{2}{|c|}{ Fairey et al., 2001; Woofter et al., 2003} \\
\hline & RIA & Woofter et al., 20 & Woofter et al., 2005 \\
\hline & C-ELISA & Maucher et al., 2 & \\
\hline Ciguatoxin & Cytotox. assay & Bottein Dechraou & al., 2005 \\
\hline (TRACE) ELE & MENTS & & \\
\hline As & ICP-MS & Shlosberg et al., 2 & \\
\hline $\mathrm{Ba}$ & LA-ICP-MS & Hsieh et al., 2011 & \\
\hline $\mathrm{Be}$ & LA-ICP-MS & Hsieh et al., 2011 & \\
\hline $\mathbf{B i}$ & LA-ICP-MS & Hsieh et al., 2011 & \\
\hline $\mathrm{Ca}$ & LA-ICP-TOF-MS & Cizdziel, 2007 & \\
\hline & SF-ICP-MS & Langer et al., 201 & \\
\hline Cd & ICP-MS & Chaudhuri et al., & 9; Shlosberg et al., 2011b \\
\hline & SF-ICP-MS & Langer et al., 201 & \\
\hline & LA-ICP-MS & Hsieh et al., 2011 & \\
\hline Co & LA-ICP-MS & Hsieh et al., 2011 & \\
\hline $\mathrm{Cr}$ & SF-ICP-MS & Langer et al., 201 & \\
\hline Cs & SF-ICP-MS & Langer et al., 201 & \\
\hline $\mathrm{Cu}$ & LA-ICP-TOF-MS & Cizdziel, 2007 & \\
\hline & SF-ICP-MS & Langer et al., 201 & \\
\hline & LA-ICP-MS & Hsieh et al., 2011 & \\
\hline $\mathrm{Fe}$ & LA-ICP-TOF-MS & Cizdziel, 2007 & \\
\hline & SF-ICP-MS & Langer et al., 201 & \\
\hline $\mathrm{Hg}$ & ICP-MS & Chaudhuri et al., & 9; Shlosberg et al., 2011b \\
\hline K & SF-ICP-MS & Langer et al., 201 & \\
\hline Li & SF-ICP-MS & Langer et al., 201 & \\
\hline Mg & SF-ICP-MS & Langer et al., 201 & \\
\hline & LA-ICP-MS & Hsieh et al., 2011 & \\
\hline Mn & LA-ICP-MS & Hsieh et al., 2011 & \\
\hline Mo & SF-ICP-MS & Langer et al., 201 & \\
\hline $\mathrm{Na}$ & SF-ICP-MS & Langer et al., 201 & \\
\hline $\mathbf{N i}$ & SF-ICP-MS & Langer et al., 201 & \\
\hline & LA-ICP-MS & Hsieh et al., 2011 & \\
\hline $\mathbf{P}$ & SF-ICP-MS & Langer et al., 201 & \\
\hline
\end{tabular}




$\begin{array}{lll}\text { Pb } & \text { AAS } & \text { Cernik et al., 1971; Verebey et al., } 1991 \\ & \text { GFAAS } & \text { Shen et al., 2003 } \\ & \text { SS-GFAAS } & \text { Resano et al., 2007 } \\ \text { ICP-MS } & \text { El-Hajjar et al., 2007; Chaudhuri et al., 2009; Shlosberg et al., 2011b } \\ & \text { LA-ICP-TOF-MS } & \text { Cizdziel, 2007 } \\ & \text { SF-ICP-MS } & \text { Langer et al., 2010 } \\ & \text { LA-ICP-MS } & \text { Hsieh et al., 2011 } \\ & \text { SF-ICP-MS } & \text { Langer et al., 2010 } \\ \text { Rb } & \text { SF-ICP-MS } & \text { Langer et al., 2010 } \\ \text { S } & \text { LA-ICP-MS } & \text { Hsieh et al., 2011 } \\ \text { Sb } & \text { AAS } & \text { Lombeck et al., 1989 } \\ \text { Se } & \text { ICP-MS } & \text { Shlosberg et al., 2011b } \\ & \text { LA-ICP-MS } & \text { Hsieh et al., 2011 } \\ \text { TI } & \text { LA-ICP-TOF-MS } & \text { Cizdziel, 2007 } \\ \mathbf{V} & \text { LA-ICP-TOF-MS } & \text { Cizdziel, 2007 } \\ \text { Zn } & \text { SF-ICP-MS } & \text { Langer et al., 2010 } \\ & \text { LA-ICP-MS } & \text { Hsieh et al., 2011 }\end{array}$


Table 1. Overview of the analytes discussed in this review, with referral to the utilized analytical techniques.

Abbreviations: AAS: atomic absorption spectrometry; C-ELISA: Competitive enzyme-linked immunosorbent assay; GC-ECD: Gas chromatography with electron capture detection; GC-HRMS: Gas chromatography with high resolution mass spectrometric detection; GC-MS: Gas chromatography with mass spectrometric detection; IC-MS/MS: Ion chromatography with tandem mass spectrometric detection; ICP-MS: Inductively coupled plasma mass spectrometry; LA-ICP-MS: Laser ablation inductively coupled plasma mass spectrometry; LA-ICP-TOF-MS: Laser-ablation inductively coupled plasma time-of flight mass spectrometry; LC-MS: Liquid chromatography with mass spectrometric detection; LC-MS/MS: Liquid chromatography with tandem mass spectrometric detection; R-binding assay: Receptor-binding assay; RIA: Radio-immuno assay; SF-ICP-MS: Sector-field inductively coupled plasma mass spectrometry; SS-GFAAS: solid sampling graphite furnace atomic absorption spectrometry 